\section{A REVIEW ON APPLICATION OF WASTE COOKING OIL AS REJUVENATOR IN POROUS ASPHALT MIXTURE}

Wan Nur Aifa Wan Azahara, Mastura Bujanga, Ramadhansyah Putra Jayaa*, Mohd. Rosli Hainina, Norzita Ngadib, Mohd Ezree Abdullahc, Abdullahi Ali Mohamedd

aDepartment of Geotechnics and Transportation, Faculty of Civil Engineering, Universiti Teknologi Malaysia, 81310 UTM Johor Bahru, Johor, Malaysia

bDepartment of Chemical Engineering, Faculty of Chemical Engineering, Universiti Teknologi Malaysia, 81310 UTM Johor Bahru, Johor, Malaysia

cFaculty of Civil and Environmental Engineering, Universiti Tun Hussein Onn Malaysia , 86400 Batu Pahat, Johor, Malaysia dFaculty of Engineering, The University of Nottingham Malaysia Campus, Jalan Broga, 43500 Semenyih, Selangor Darul Ehsan, Malaysia.
Article history

Received

30th April 2015

Received in revised form

$27^{\text {th }}$ August 2015

Accepted

1st October 2015

*Corresponding author ramadhansyah@utm.my

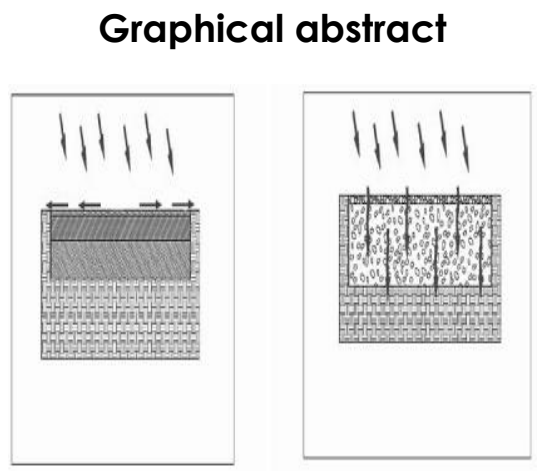

\begin{abstract}
Aging process of bitumen is one of the main obstacles, which limit the implementation of porous pavement. An aging process would cause a shorter service life of porous asphalt compared to the conventional hot mix asphalt mixture. The tendency rate of aging processes in porous asphalt is high due to the exposure of bitumen and aggregates binding in an open-graded structure that maximizes oxidation process to occur thus producing aged binder. In this respect to restore the original characteristics of pavement from aged bitumen, rejuvenation of bitumen binder offers an effective option. From the previous research, the performance of waste cooking oil (WCO) is investigated and indicated as one of rejuvenator agents for bitumen regeneration. Thus, this paper reviewed the novelty of the WCO, as an alternative natural rejuvenating agent for aged bitumen to a condition that resembles the original bitumen in the asphalt mixture.
\end{abstract}

Keywords: Porous asphalt pavement; aging process; rejuvenation; waste cooking oil (WCO)

(C) 2016 Penerbit UTM Press. All rights reserved

\subsection{INTRODUCTION}

Porous asphalt pavement which is known as opengraded asphalt actually has the same structured layer as asphaltic concrete except for their wearing course. This type of pavement consists of coarse aggregate gradation with a relatively large nominal maximum aggregate size (NMAS) either $9.5 \mathrm{~mm}, 12.5 \mathrm{~mm}, 19.0$ $\mathrm{mm}$ or $25.4 \mathrm{~mm}$ and forming of $18-25 \%$ air-void content. Since the 1950s, this pavement is commonly used in a wearing surface as an innovative road surfacing technology where it is part of sustainable drainage 
systems [1]. According to the research done by Astebol et al. [2], the implementation of porous asphalt could manage the water runoffs more systematically compared to the conventional pavement because of its interconnected voids. Besides, permeable pavement is implemented in order to mitigate the stormwater drainage problems, especially in parking or low traffic density areas. Figure 1 shows the water runoff infiltrate into porous asphalt and conventional pavement. The water will flow on the pavement surface of conventional pavement which can cause water ponding thus affecting road user safety especially during rainfall. Meanwhile, in porous asphalt, the runoff will penetrate into the pavement before it flow to the side drain. Therefore, porous asphalt may help to reduce the noise level, headlight glare and hydroplaning problems for the traffic safety purpose [3].

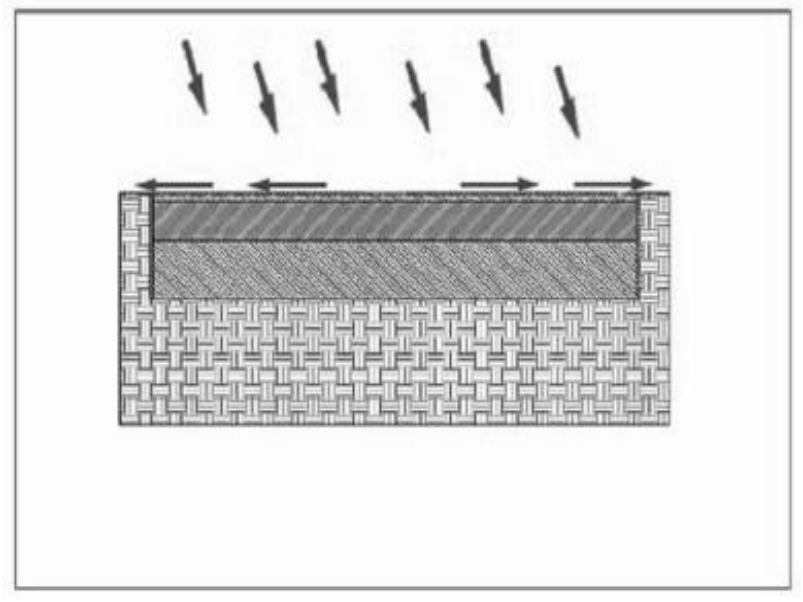

(a)

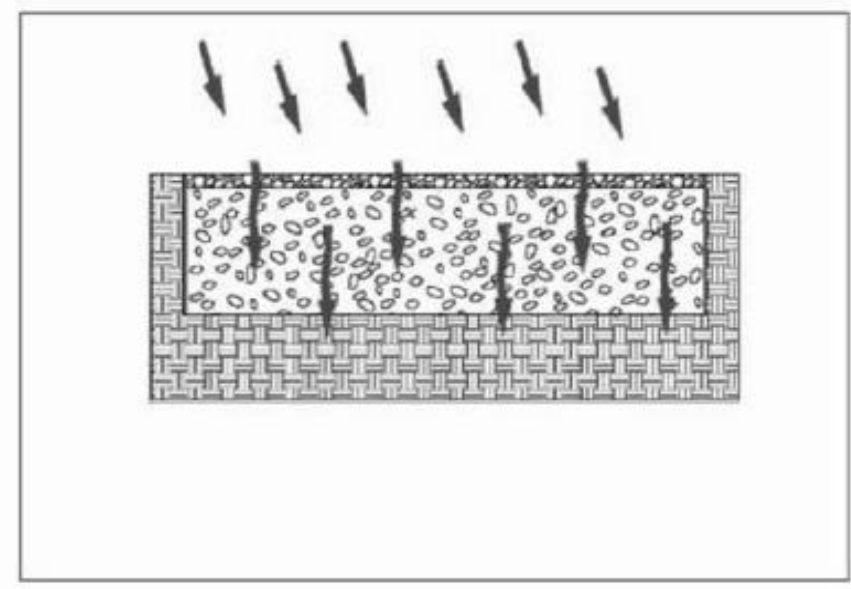

(b)

Figure 1 Rainfall water movement on traditional asphalt (a) and porous asphalt (b)

\subsection{ISSUES IN POROUS ASPHALT PAVEMENT}

\subsection{Process of Aging}

Besides, it could cause the stripping process between aggregate and bitumen when the bitumen hardens, thus may cause raveling problems. Exposion to the heat, ultraviolet (UV) light, and oxygen are factors of the aging process to occur in the pavement life cycle either during storage, mixing, transporting, lying, and service life [4-7]. For porous asphalt, the aging process occurs faster than conventional mixtures due to the high porosity and air void that expose to the oxygen, resulting the reduction of strength and fatigue resistance performance. Hence, the performance of pavement service life will be affected where the service life of porous asphalt and conventional pavement are 10-12 years and 18 years respectively [8]. The full-scale road trials in United Kingdom [9] prove the service life of porous pavement is related to a binder hardening by using the penetration drops. Loss of coating adhesion between aggregates and bitumen is part of pavement distress called raveling which might affect the performance of porous asphalt [10-12]. This is because of the particle arrangement with open air void will increase the exposure rate and lead to the premature of the bitumen, thus making it brittle [13].

\subsection{Mechanism of Bitumen Aging Process}

More than 110 million metric tons of bitumen are required in the bituminous pavement structure as an aggregate binder due to its specific characteristics. Besides, high cost was spent in highway construction, restoration, and preservation in order to control the aging process affects the storage, mixing, transportation, and pavement service life [14, 15]. For information, the main bitumen aging mechanism is the loss of volatiles and oxidation process and their rate of aging is affected by climate, aggregate, and its composition. Hence, the aged bitumen will become brittle and stiffer compared to fresh bitumen due to the changes of structure in maximum rate of the oxidation process. Cracking and surface raveling may occur due to the particle changes that lead to an adhesion loss which caused by the presence of moisture [16, 17].

Consequently, the micro-cracks will be developed between the interface of aggregates and binder when the bitumen becomes brittle [16]. Then, it will allow the aging process to occur for the whole pavement life cycle and lifetime when then bitumen compositions were exposed to the air [17]. Bitumen can be divided into two phases which are solid and liquid, namely asphaltenes and maltenes respectively. During the bitumen aging process, asphaltenes will be increased, whereas maltenes which acts as a glve will be decreased. Thus, a brittle and stiffer pavement will 
affect the rigidity of pavement due to the imbalance of the ratio between asphaltenes and maltenes [18, 19]. The oxidation process has caused the failure of maltenes to bind the pavement structures together and as a result, the cost of restoration and preservation of bituminous pavement will increase due to the surface cracking or raveling [20]. It is recommended to introduce an effective way for a better restoration of asphaltenes and maltenes compositions by implementing WCO, a high maltenes proportion based modifier as a rejuvenator in the bitumen [21]. The rejuvenator should able to withstand the hardening and temperature susceptibility in order to achieve an acceptable bitumen [22] .

\subsection{REJUVENATOR APPLICATION IN AGED BITUMEN}

The rejuvenator can be defined as an ability of product in restoring the original properties during the aging process such as maintaining the original ratio of asphaltenes and maltenes in bitumen properties. It is used to mitigate the cracks production and govern the fines loss surface of pavement. According to the rejuvenating theory, the oxidized asphalt compositions should be added an acceptable proportion of rejuvenator in order to create a new asphalt binder and recover the aged bitumen performance [23-25]. In addition, rejuvenator of asphalt consist of anti-aging components, plasticizers, and certain additives to help in improving their performance in asphalt pavement [26-29]. There are several methods can be used to reduce the pavement failures like surface raveling which are the application of fog seals, rejuvenator emulsions, and thin overlay technology [30]. Based on the researches done, WCO has proved its function as rejuvenator to enhance the similar characteristics of aged bitumen as fresh bitumen [31]. Moreover, WCO has a potential to increase the asphalt pavement lifetime for several years before reconstruction and as a result, the cost of annual pavement maintenance can be reduced. There are three beneficial reactions that were offered by asphalt rejuvenator emulsion, which are [30]:

a) The life cycle of pavement can be prolonged due to the increasing of penetration value and decreasing rate of binder viscosity at the surface pavement;

b) Oxidation process can be decelerated by sealing the pavement to avoid the penetration of water and air, eventually reducing ravelling, stripping, and protecting the pavement more depth;

c) The durability of bitumen in pavement can be increased due to the balancing chemical portions of asphalt binder

There are few guidelines for rejuvenator that must be followed include [30]: a) In order to balance and improve the ratio of maltenes and asphaltenes, the portions of maltenes should be in rejuvenator;

b) Several bitumen tests such as viscosity, penetration, and abrasion loss need to be conducted for pavement durability evaluation;

c) Penetration of bitumen into the pavement should be ensured in order to ease the fluxing or absorption chemical processes

\subsection{Waste Cooking Oil (WCO) in Aged Bitumen}

The grease wastes or non-edible oil, which is produced during the food production or cooking can be described as WCO. Mostly, the authorized companies obtain and collect WCO either from the restaurants, residential area, food industry, or recycling centers [32, 33]. This waste created a significant amount of challenges in the management of the oils, causing the disposal problems to happen as well as possibly contaminate the land and water resources. Thus, WCO should be used as a binder modifier or rejuvenator to soften the bitumen [34] due to its similarity in asphalt (maltenes) that contains unsaturated fatty acids. According to Kuang et al. [35] and Guern et al. [36], a new binder from aged bitumen can be achieved by adding an oil that has low viscosity. Table 1 shows the chemical compositions in fresh, aged, and rejuvenated binder [21, 37]. Based on results in Table 1, fresh bitumen comprise higher maltenes compared to asphaltenes components. Then, the value of maltenes decreases in aged bitumen during the oxidation process. The value of maltenes constituent increase when WCO is added in the bitumen and the process known as rejuvenation. WCO can be utilized as rejuvenator in aged binder due to its characteristic similar to original asphalt in the penetration result [38-40]. However, the use of rejuvenator in bitumen has its limitation in penetration which is less than $2 \mathrm{~cm}$. In order to apply rejuvenator in asphalt binder efficiently, embedded capsule with rejuvenator is proposed and introduced [41].

Table 1 Chemical components of virgin bitumen and WCO rejuvenated bitumen [40]

\begin{tabular}{|c|c|c|c|}
\hline Designation & $\begin{array}{c}\text { Asphaltenes } \\
\text { (wt. \%) }\end{array}$ & $\begin{array}{l}\text { Maltenes } \\
\text { (wt. \%) }\end{array}$ & $\begin{array}{c}\text { Asphaltenes/ } \\
\text { Maltenes } \\
\text { (\%) }\end{array}$ \\
\hline $\begin{array}{l}\text { Original } \\
\text { bitumen }\end{array}$ & 9.23 & 90.77 & 10.17 \\
\hline $\begin{array}{c}\text { Aged } \\
\text { bitumen }\end{array}$ & 10.98 & 89.02 & 12.34 \\
\hline $\begin{array}{c}\text { Rejuvenate } \\
\text { bitumen }\end{array}$ & 9.69 & 90.31 & 10.73 \\
\hline
\end{tabular}




\subsubsection{Rejuvenator Encapsulation}

The implementation of encapsulation rejuvenator inside a binder is an effective method to overcome its limitation [14]. The rejuvenator and asphalt will be mixed together and placed in a hard porous stone capsules to withstand the high temperatures, process of mixing and compaction, and pavement structures [42]. In addition, it can be assumed that its aging level will be reverted when the rejuvenator released the asphalt and the pavement service life also can be prolonged. Figure 2 shows the mechanism of rejuvenator capsule, which is divided into three sections; Point 1, Point 2, and Point 3. Point 1 shows the capsule is embedded in the pavement and need to withstand the traffic loads. During the several years of service, the asphalt will become stiffer and force will be distributed on the surface of capsules. At Point 2, the high loads from traffic and asphalt aging process will force the capsule to crack. Point 3 shows that the rejuvenator inside the capsule will come out due to the increasing rate of pressure in the capsule. Then, aged asphalt concrete will be softened by oil diffusion through the binder and the original property of bitumen will be restored when the rejuvenator is released.

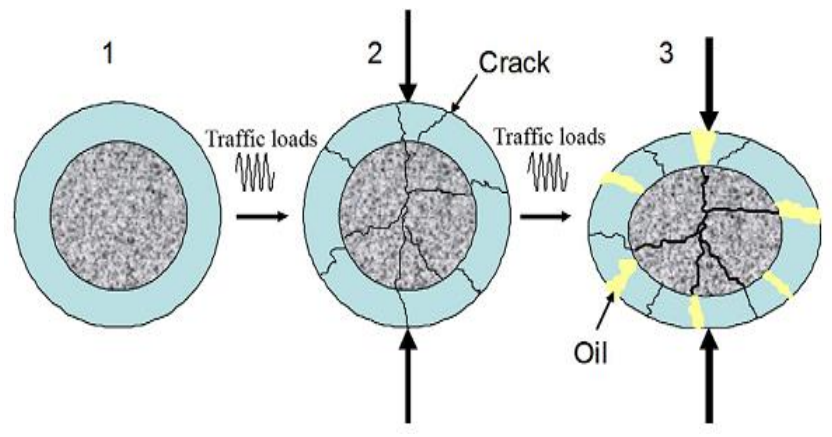

Figure 2 Capsules mechanism scheme [42]

\subsection{CONCLUSION}

According to the previous studies done by researchers, aging process is a main problem that might affect the application of porous asphalt in highway construction. This process will occur when the bituminous binder oxidized which involves the two main components in bitumen matrix, named maltenes and asphaltenes. The aged bitumen can be achieved through the oxidation process and might cause the pavement failures include surface raveling and cracking. Therefore, waste cooking oil is introduced as a rejuvenator to restore the properties of aged binder. Besides, its performance, as a rejuvenating agent is proven by the results of maltenes and asphaltenes ratio in the mixtures.

\section{Acknowledgement}

The support provided by Malaysian Ministry of Higher Education (MOHE) and Universiti Teknologi Malaysia (UTM) in the form of a research grant number Q.J130000.2522.09H67 and Q.J130000.2422.02G83 for this study is very much appreciated.

\section{References}

[1] Abustan, I. 2012. Review of Permeable Pavements System in Malaysia Conditions. OIDA International Journal of Sustainable Development. 04(02): 27-36.

[2] Astebol, S. O., Hvitvet, J. T. and Simonsena, A. 2004. Sustainable Storm Water Management at Fornebu-From an Airport to an Industrial and Residential Area of the City of Oslo, Norway. Science of the Total Environment. 334335(Special Issues): 23949

[3] Sasana, P. and Ismanto, B. S. 2003. The Influence of Using Local Materials on Quality of Porous Asphalt in Indonesia. Proceedings of the Eastern Asia Society for Transportation Studies. 4.

[4] Hoban, T. W. S., Liversedge, F. and Searby, R. 1985. Recent Developments in Pervious Macadam Surfaces. Proc. 3rd Eurobitumen Symp. 635-640.

[5] Yu, J. Y., Feng, P.C., Zhang, H. L. and Wu, S. P. 2009. Effect of Organo-Montmorillonite on Aging Properties of Asphalt. Construction and Building Materials. 23: 2636-2640.

[6] Juyal, P., Merino-Garcia, D. and Andersen, S. I. 2005. Effect on Molecular Interactions of Chemical Alteration of Petroleum Asphaltenes. Energy Fuel. 19: 1272-1281.

[7] Masson, J.F. and Gagne, M. 2008. Polyphosphoric Acid (PPA)-Modified Bitumen: Disruption Of The Asphaltenes Network Based On The Reaction Of Nonbasic Nitrogen with PPA. Energy Fuel. 22: 3402-3406.

[8] Moa, L. T., Huurman, M., Woldekidan, M. F., Wub, S. P. and Molenaar, A. A. A. 2010. Investigation into Material Optimization and Development for Improved Ravelling Resistant Porous Asphalt Concrete. Materials and Design. 31: 3194-3206

[9] Daines, M. E. 1992. Trials of Porous Asphalt and Rolled Asphalt on the A38 at Burton. Department of transport TRRL Report RR323, Transport and Road Research Laboratory, Crowthorne.

[10] Cooley, L. A., Brumfield, J. W., Mallick, R. B., Mogawer, W. S., Partl, M. and Poulikakos, L. 2009. Construction and Maintenance Practices for Permeable Friction Courses. Report Number 640. National Cooperative Highway Research Program. Washington D.C.

[11] Kandhal, P. 2002. Design, Construction and Maintenance of Open-Graded Asphalt Friction Courses. Information Series 115. National Asphalt Pavement Association. Lanham, MD.

[12] Alvarez, A. E., Epps, M. A., Estakhri, C. and Izzo, R. 2010. Evaluation of Durability Tests for Permeable Friction Course Mixtures. International Journal Pavement Engineering. $11(1): 49-60$

[13] Kandhal, P. and Mallick, R. 1998. Open-graded Friction Course: State Of The Practice. Report Number E-C005. Transportation Research Circular.

[14] Garcíaa, Á., Schlangen, E., Ven, M. and Sierra-Beltrána, G. 2010. Preparation of Capsules Containing Rejuvenators for Their Use in Asphalt Concrete. Journal of Hazard Materials. 184: 603-11.

[15] LU, X. H. and Isacsson, U. 1998. Chemical and Rheological Evaluation of Ageing Properties Of SBS Polymer Modified Bitumens. Fuel. 77(9-10): 961-72.

[16] Branthaver, J. F. J. C., Petersen, R. E., Robertson, J. J., Duvall, S. S., Kim, P. M., Harnsberger, T., Mill, E.K., Ensley, F.A., Barbour, J.F. and Schabron. 1993. Binder Characterization 
and Evaluation. Chemistry, Volume 2, SHRP-A-368, National Research Council, Washington, D.C.

[17] Hunter, R.N. 1997. Bituminous Mixtures in Road Construction. Thomas Telford, London.

[18] Leseur, D. 2009. The Colloidal Structure of Bitumen: Consequences on the Rheology and On the Mechanisms of Bitumen Modification. Advances in Colloid and Interface Science. 145(1-2): 42-82.

[19] Zhang, F., YU, J. and Hanun, J. 2011. Effects of Thermal Oxidative Ageing on Dynamic Viscosity. TG/DTG, DTA and FTIR of SBS- and SBS/Sulfur Modified Asphalts. Construction and Building Materials. 25(1): 129-137.

[20] Asphalt Institute 2013. Asphalt Pavement Distress Summary www.asphaltinstitute.org.

[21] Shen, J, Amirkhanian, S. and Miller, J. A. 2007. Effects of Rejuvenating Agents On Superpave Mixtures Containing Reclaimed Asphalt Pavement. Journal of Materials in Civil Engineering. 19(5): 376-384.

[22] Peterson, G. D., Davison, R.R., Glover, C. J. and Bulin, J. A. 1994. Effect of Composition on Asphalt Recycling Agent Performance. Transportation Research Record. 1436: 3846.

[23] Silva, H., Oliveira, J. and Jesus, C. 2012. Are Totally Recycled Hot Mix Asphalts A Sustainable Alternative For Road Paving? Resources, Conservation and Recycling. 60: 3848.

[24] Su, J. and Schlangen, E. 2012. Synthesis and Physicochemical Properties Of High Compact Microcapsules Containing Rejuvenator Applied In Asphalt. Chemical Engineering Journal. 198-199: 289-300.

[25] Doh, Y., Amirkhanian, S. and Kim, K. 2008. Analysis of Unbalanced Binder Oxidation Level in Recycled Asphalt Mixture Using GPC. Construction and Building Materials. 22:1253-60.

[26] Huang, Y., Bird, R. and Heidrich, O. 2007. A Review of the Use of Recycled Solid Waste Materials in Asphalt Pavements. Resources, Conservation and Recycling. 52: 58-73.

[27] Aravind, K. and Das, A. 2007. Pavement Design with Central Plant Hot-Mix Recycled Asphalt Mixes. Construction and Building Materials. 21: 928-36.

[28] Miliutenko, S., Björklund, A. and Carlsson, A. 2013. Opportunities for Environmentally Improved Asphalt Recycling: The Example of Sweden. Journal Clean Production. 43: 156-65.

[29] Shu, X., Huang, B. and Vukosavljevic, D. 2008. Laboratory Evaluation of Fatigue Characteristics of Recycled Asphalt Mixture. Construction and Building Materials. 22: 1323-30.
[30] Boyer, R. E. 2000. Asphalt Rejuvenators: Fact or Fable. In Transportation System 2000 (TS2K) Workshop, San Antonio Texas

[31] Karlsson, R. and Isacsson, U. 2006. Material-Related Aspects of Asphalt Recycling-State of the Art. Journal Materials in Civil Engineering. 18(1): 81-92.

[32] Singhabhandhu, A. and Tezuka, T. 2010. The Waste-ToEnergy Framework For Integrated Multi-Waste Utilization: Waste Cooking Oil, Waste Lubricating Oil, And Waste Plastics Energy. Energy. 35(6): 2544-2551.

[33] Zhang, H., Wang, Q. and Mortimer, S.R. 2012. Waste Cooking Oil As An Energy Resource: Review Of Chinese Policies. Renewable and Sustainable Energy Reviews. 16(7): 5225-5231

[34] Asphaltrejuvenation (US Patent) US20100034586Al, http://www.faqs.org/patents/app/20100034586.

[35] Özbay, N., Oktar, N. and Tapan, N.A. 2008. Etherification of Free Fatty Acids in Waste Cooking Oils (WCO): Role of Ion-Exchange Resins. Fuel. 87(10-11): 1789-1798.

[36] Kuang, D.L., YU, J.Y., Cai, Z.W. and Song, X.D. 2011. Effect of Rejuvenator on Properties of Aged Bitumen of Different Aging Degree. Highway (in Chinese). 5: I53-157.

[37] Guern, M. L., Chailleux, E., Farcas, F., Dreesen, S. and Maibille, I. 2010. Physico-Chemical Analysis of Five Hard Bitumens: Identification of Chemical Species and Molecular Organization Before and After Artificial Aging. Fuel. 89: 3330-3339.

[38] Asli, H. and Karim, M.R. 2010. Effect of Waste Cooking Oil as a Rejuvenating Agent for Aged Bituminous Pavement. The $8^{\text {th }}$ International Conference on Geotechnical Ad Transportation Engineering, Malaysia.

[39] Hallizza, A., Esmaeil, A., Majid, Z. and Mohamed, R.K. 2012. Investigation on Physical Properties of Waste Cooking OilRejuvenated Bitumen Binder. Construction and Building Materials. 37: 398-405.

[40] Majid, Z., Esmaeil, A., Hallizza, A. and Mohamed, R.K. 2012 Investigation of the Possibility of Using Waste Cooking Oil as a Rejuvenating Agent for Aged Bitumen. Journal of Hazardous Materials. 233-234: 254-258.

[41] Chiu, C.T. and Lee, M.G. 2006. Effectiveness of Seal Rejuvenators for Bituminous Pavement Surfaces. Journal of Testing and Evaluation. 34: 390-394.

[42] García, A., Schlangena, E. and Van de Ven, M. 2011. Properties of Capsules Containing Rejuvenators for Their Use in Asphalt Concrete. Fuel. 90: 583-591. 